Asian-Australasian Journal of

Food Safety and Security

ISSN 2523-1073 (Print) 2523-2983(Online)

https://www.ebupress.com/journal/aajfss/

\title{
Article \\ Monitoring of pesticide residues in vegetables collected from retail markets of Dhaka district of Bangladesh using QuEChERS Extraction and Gas Chromatography
}

\author{
Rakibul Hasan ${ }^{1}$, Md. Mahadi Alam ${ }^{1}$, S M Mizanur Rahman ${ }^{1}$, Deeder Sultana ${ }^{2}$ and Mohammad Dalower Hossain \\ Prodhan $^{3 *}$ \\ ${ }^{1}$ Department of Entomology, Sher-e-Bangla Agricultural University, Dhaka-1207, Bangladesh \\ ${ }^{2}$ Planning \& Evaluation Wing, Bangladesh Agricultural Research Institute, Gazipur-1701, Bangladesh \\ ${ }^{3}$ Pesticide Analytical Laboratory, Pesticide Research \& Environmental Toxicology Section, Entomology \\ Division, Bangladesh Agricultural Research Institute, Gazipur-1701, Bangladesh
}

*Corresponding author: Mohammad Dalower Hossain Prodhan, Pesticide Analytical Laboratory, Pesticide Research \& Environmental Toxicology Section, Entomology Division, Bangladesh Agricultural Research Institute, Gazipur-1701, Bangladesh. Phone: +8801819849657; E-mail: dalowerag @yahoo.com; mdhprodhan@gmail.com

Received: 27 August 2021/Accepted: 21 November 2021/ Published: 30 November 2021

Copyright () 2021 Rakibul Hasan et al. This is an open access article distributed under the Creative Commons Attribution 4.0 International License (https://creativecommons.org/licenses/by/4.0/), which permits unrestricted use, distribution, and reproduction in any medium, provided the original work is properly cited.

\begin{abstract}
The present study was aimed to detect and quantify major organophosphorus pesticide residues in cauliflower and cucumber collected from different retail markets of Dhaka city, Bangladesh. In this study, a total of 50 vegetable samples (30 samples of cauliflower and 20 samples of cucumber) were analyzed using Quick, Easy, Cheap, Effective, Rugged and Safe (QuEChERS) extraction technique and Gas Chromatography coupled with Flame Thermionic Detector (GC-FTD). Among the 30 analyzed samples of cauliflower, 5 samples (16.7\% of the total number of samples) contained residues of chlorpyrifos, quinalphos, acephate and dimethoate, where 4 samples contained multiple pesticide residues. All the contaminated samples of cauliflower contained residues above the EU-MRL. On the other hand, among the 20 analyzed samples of cucumber, only 2 samples (10\% of the total number of samples) contained residues of quinalphos and chlorpyrifos at a level being below the EU-MRL. This study reflects the overall scenario of pesticide residues remain in cauliflower and cucumber purchased from different local markets of Dhaka city, which will help the consumer to be aware of their health and safety. The findings derived from this study reveals the public health concern due to the potential of pesticide toxicity in vegetables for the consumers. Therefore, continuous monitoring on the use of pesticides in vegetables should be strengthened.
\end{abstract}

Keywords: organophosphorus pesticide residues; vegetables; QuEChERS extraction; gas chromatography

\section{Introduction}

Vegetables are commonly used to fulfill the balance diet requirement as they are a vital source of vitamins and fiber. It makes up a major portion of the diet of humans in many parts of the world and play a significant role in human nutrition, especially as sources of vitamins (C, A, B1, B6, B9, E), minerals, dietary fiber and phytochemicals (Wargovich, 2000; Dias and Ryder, 2011). The cauliflower and cucumber are the two important vegetables grown commercially in Bangladesh. Cauliflower is low in fat, high in dietary fiber, contains water and vitamin $\mathrm{C}$, possessing a very high nutritional density. The warm and humid climatic condition of the 
country, increase use of modern high yielding varieties of crops and more use of chemical fertilizers are highly favorable for development and multiplication of pests and diseases. In Bangladesh context, the cauliflower growers have been using pesticides frequently to have the higher yield. But the over doses of pesticides make the residue problem, which might pollute our food and be harmful for our health. Cucumbers provide a unique combination of nutrients, including antioxidant, vitamin C, beta-carotene, and manganese (Yang et al., 2006).

In order to reduce the loss and maintain the quality of fruits and vegetables, pesticides are used together with other pest management techniques during cropping to destroy pests and prevent diseases. However, pesticides create several adverse effects not only in the human health, but also in the environment. Pesticide being toxic can become a potential hazard to the manufacturers, the users, the public at large and the environment. Pesticide can produce negative impacts, both socially and economically (Antle and Pingali, 1994). Extensive use of pesticides has resulted in contamination of vital supplies, air, water, and food, the risk to humans may be short term as well as long term depending on the persistence of the pesticide and the exposure period. In Bangladesh, it has been reported that farmers sprayed insecticides quite frequently even every day in vegetables (Anon., 2000). Serious consequences of indiscriminate, overuse and misuse of pesticides results in a disruption in the agro-ecosystem, human health hazard and environmental pollution (MacIntyre et al., 1989).

In Bangladesh, farmers have no idea about the pesticide residues in the food as well as their ill effect on human health and the environment. The whimsical spray of insecticides and selling of vegetables after one to two days of spray application are assumed to be a normal practice. There is no insecticide available, whose retention period is less than three to five days (Rahman, 1999). The present pattern of pesticide usage in Bangladesh particularly in vegetables led to assume that majority of marketed vegetables contain pesticide residue more than Maximum Residue Limit (Kabir et al., 2007). As crop production and pesticides are closely related and their left over residues might or might not persist in the environment that should be carefully examined and monitored. The detection and monitoring of pesticide residues, particularly in vegetable and fruits is being done in regular fashion in many countries (Kumari et al., 2004).

In order to determine pesticide residues, effective extraction and clean-up methods are essential. At present the quick, easy, cheap, effective, rugged and safe (QuECHERS) extraction method is widely used for extraction and clean up of pesticide residues in a wide variety of matrices (Prodhan et al., 2018; 2016; 2016a; 2015; 2015a). This method is gaining popularity day by day compared to the other existing methods as it has a lot of advantages. The important ones are high recoveries of analytes with low organic solvent consumption and the low cost per sample. Gas Chromatography is widely used for the quantification of pesticide residues in vegetables, fruits (Prodhan et al., 2021), fish (Prodhan et al., 2018a; 2010; 2009) and other matrices including betel leaf, and water (Prodhan et al., 2021a; 2021b), as they are very much sensitive for the selected pesticides of this study.

Pesticide residue in food has become a consumer's safety issue and the consumers have the right to know how much pesticide get incorporated in the food they eat. The identification and quantification of pesticide residues in the food are becoming the public interest. Till today, several research works have been conducted on the presence of pesticide residues in vegetables in Bangladesh (Habib et al., 2021; Nahar et al., 2020; Islam et al., 2021; 2019; 2019a; Ahmed et al., 2021; 2021a; 2019; Prodhan et al., 2018b; 2018c; Hossain et al., 2014; Islam et al., 2014; Kabir et al., 2008; 2008a). Nevertheless, more research work is needed to find out the actual scenario of pesticide residues remain in vegetables. Keeping this view, the present study was initiated to detect and quantify seven organophosphorus pesticide residues in cauliflower and cucumber collected from different retail markets of Dhaka city of Bangladesh.

\section{Materials and Methods}

\subsection{Chemicals and reagents}

The standard of chlorpyrifos, acephate, diazinon, dimethoate, quinalphos, malathion and fenitrothion were obtained from Sigma-Aldrich Laborchemikalien (St Louis, MO, USA) via Bangladesh Scientific Pvt. ltd. Dhaka, Bangladesh. Standards of all the pesticides contained $>99.6 \%$ purity. Methanol, acetone, gradient grade acetonitrile, sodium chloride $(\mathrm{NaCl})$, anhydrous magnesium sulphate $\left(\mathrm{MgSO}_{4}\right)$ and Primary Secondary Amine (PSA) were purchased from Bangladesh Scientific Pvt. ltd. Dhaka, Bangladesh.

\subsection{Preparation of pesticide standard solution}

Pesticide standard stock solutions of chlorpyrifos, acephate, diazinon, dimethoate, quinalphos, malathion and fenitrothion were prepared separately in acetonitrile at a concentration of $1000 \mathrm{mg} / \mathrm{L}$ and stored at $-20^{\circ} \mathrm{C}$ until use. A mixed standard solution of $50 \mathrm{mg} / \mathrm{L}$ in acetonitrile containing all the aforementioned pesticides was prepared by adding the appropriate volume of each individual stock solution in a $50 \mathrm{ml}$ volumetric flask and 
made to volume by addition of acetonitrile. An intermediate mixed standard solution of $10 \mathrm{mg} / \mathrm{L}$ in acetonitrile was prepared from the mixed standard solution of $50 \mathrm{mg} / \mathrm{L}$. Then working standard solutions of $0.1,0.2,0.5$, $1.0,2.0,3.0$, and $5.0 \mathrm{mg} / \mathrm{L}$ in acetonitrile were prepared by transferring the appropriate amount from $10 \mathrm{mg} / \mathrm{L}$ intermediate mixed standard solution into ten separate $10-\mathrm{mL}$ volumetric flasks. All the standard solutions were kept in a freezer at $-20^{\circ} \mathrm{C}$ until use.

\subsection{Sample collection and sample preparation}

A total of 50 samples (30 cauliflower \& and 20 cucumber) were collected for this study. The samples were collected from 5 retail markets (Banani Bazar, Rampura Bazar, Mohammadpur Krishi Market, Kawran Bazar and Jatrabari Bazar) of Dhaka city. Six samples of cauliflower and four samples of cucumber were collected from each market. The amount of each sample was $1 \mathrm{Kg}$ for all the selected vegetables. The samples were collected in clean transparent air tight polyethylene bag and each bag was properly labeled with sample number and sources. Individual sample was collected in individual polyethylene bag to avoid cross contamination. The collected samples were taken to the Pesticide Analytical Laboratory, Pesticide Research \& Environmental Toxicology Section, Entomology Division, Bangladesh Agricultural Research Institute (BARI) on the day of collection. The whole unit of each sample cut into small pieces and mixed properly. Clean air tight polythene bags were used to store chopped sample in a refrigerator at $-20^{\circ} \mathrm{C}$ until extraction and cleanup process.

\subsection{Extraction and clean up}

In this study, the QuEChERS extraction technique was used for the extraction and clean-up of samples which was modified by Prodhan et al. 2015. The chopped samples were grounded thoroughly with the fruit blender. A representative $10 \mathrm{-g}$ portion of thoroughly homogenized sample was weighted in a $50 \mathrm{~mL}$ polypropylene centrifuge tube. Then $10 \mathrm{~mL}$ of acetonitrile $(\mathrm{MeCN})$ was added into the centrifuge tube. The centrifuge tube was closed properly and shaken vigorously for $30 \mathrm{~s}$ by the use of a vortex mixer. Then, $4 \mathrm{~g}$ of anhydrous $\mathrm{MgSO}_{4}$ and $1 \mathrm{~g}$ of $\mathrm{NaCl}$ were added into the centrifuge tube, and it was shaken immediately by the vortex mixer for 1 minute to prevent the formation of magnesium sulfate aggregates. Afterwards, the extract was centrifuged for 5 min at $5000 \mathrm{rpm}$. An aliquot of $3 \mathrm{~mL}$ of the MeCN layer was transferred into a $15 \mathrm{~mL}$ micro centrifuge tube containing $600 \mathrm{mg}$ anhydrous $\mathrm{MgSO}_{4}$ and $120 \mathrm{mg}$ Primary Secondary Amine (PSA). Then it was thoroughly mixed by vortex for $30 \mathrm{~s}$ and centrifuged for 5 minutes at $4000 \mathrm{rpm}$. (Laboratory Centrifuges, Sigma-3K30, Germany). After centrifuge, a $1 \mathrm{~mL}$ supernatant was filtered by a $0.2 \mu \mathrm{m}$ PTFE filter, and then it was taken in a clean GC vial for injection.

\subsection{Instrumental analysis}

A Gas Chromatograph (GC-2010 Shimadzu) coupled to Flame Thermionic Detector (FTD) was used for the quantification of selected organophosphorus pesticides (acephate, malathion, diazinon, chlorpyrifos, quinalphos, fenitrothion, and dimethoate). Separations were done by Restek Rtx-OPPesticide 2 capillary column (30 m long, $0.32 \mathrm{~mm}$ i.d and $0.32 \mu \mathrm{m}$ film thicknesses), helium was used as carrier and make up gas as well. The column flow rate was $1.5 \mathrm{~mL} / \mathrm{min}$. The temperature for the injector and the detector was set to $250{ }^{\circ} \mathrm{C}$ and $280{ }^{\circ} \mathrm{C}$, respectively, and for the column oven, the temperature was programmed, which was started from $150{ }^{\circ} \mathrm{C}(1 \mathrm{~min}$ hold) and went up to $220^{\circ} \mathrm{C}$ with an incremental rate of $10^{\circ} \mathrm{C}$ ( 2 min hold). Spit mode was used for the injection of samples $(1 \mu \mathrm{L})$ and the split ratio was 10.0. The total run time was 10 min. Identification was performed by comparing the retention time of the prepared matrix matched standard and the quantification was done using the calibration curve prepared with matrix matched calibration standard. A typical chromatogram containing the seven selected pesticides are presented in Figure 1.

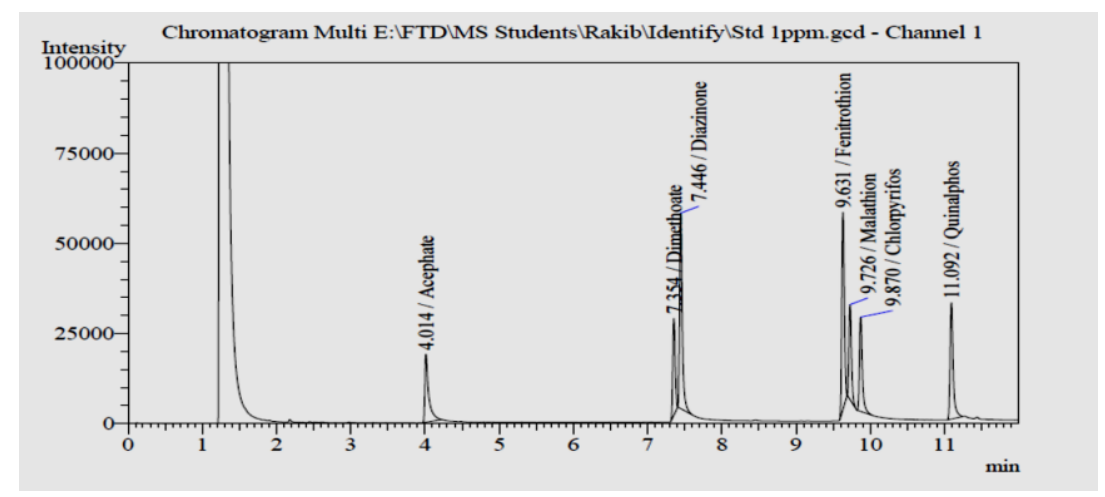

Figure 1. Typical chromatograms of seven organophosphorus insecticide standards run by GC-FTD. 


\section{Results and Discussion}

\subsection{Pesticide residues in cauliflower}

The concentrated extracts of cauliflower samples collected from different markets of Dhaka city were analyzed by GC-2010 (Shimadzu) with Flame Thermionic Detector (FTD) with the pre-set parameters. The level of pesticide residues found in the analyzed cauliflower samples and their maximum residue levels are presented in Table 1.

Table 1. The level of residues ( $\mathrm{mg} / \mathrm{kg}$ ) of different pesticides found in the analyzed cauliflower samples.

\begin{tabular}{|c|c|c|c|c|}
\hline Area of collection & Sample ID & Detected pesticides & $\begin{array}{l}\text { Level of residues } \\
(\mathrm{mg} / \mathrm{kg})\end{array}$ & $\begin{array}{l}\text { EU-MRLs } \\
(\mathrm{mg} / \mathrm{kg})\end{array}$ \\
\hline \multirow[t]{6}{*}{ Banani Bazar } & DMCF1 & ND & - & - \\
\hline & DMCF2 & ND & - & - \\
\hline & DMCF3 & ND & - & - \\
\hline & DMCF4 & ND & - & - \\
\hline & DMCF5 & $\begin{array}{l}\text { Chlorpyrifos } \\
\text { Quinalphos }\end{array}$ & $\begin{array}{l}0.022 \\
0.121 \\
\end{array}$ & $\begin{array}{l}0.05 \\
0.01 \\
\end{array}$ \\
\hline & DMCF6 & ND & - & - \\
\hline \multirow{6}{*}{ Rampura Bazar } & DMCF7 & ND & - & - \\
\hline & DMCF8 & ND & - & - \\
\hline & DMCF9 & ND & - & - \\
\hline & DMCF10 & ND & - & - \\
\hline & DMCF11 & $\begin{array}{l}\text { Chlorpyrifos } \\
\text { Quinalphos }\end{array}$ & $\begin{array}{l}0.038 \\
0.046 \\
\end{array}$ & $\begin{array}{l}0.05 \\
0.01 \\
\end{array}$ \\
\hline & DMCF12 & ND & - & - \\
\hline \multirow{6}{*}{$\begin{array}{l}\text { Mohammadpur Krishi } \\
\text { Market }\end{array}$} & DMCF13 & ND & - & - \\
\hline & DMCF14 & ND & - & - \\
\hline & DMCF15 & ND & - & - \\
\hline & DMCF16 & ND & - & - \\
\hline & DMCF17 & ND & - & - \\
\hline & DMCF18 & ND & - & - \\
\hline \multirow[t]{6}{*}{ Jatrabari Bazar } & DMCF19 & $\begin{array}{l}\text { Acephate } \\
\text { Chlorpyrifos } \\
\text { Quinalphos }\end{array}$ & $\begin{array}{l}0.008 \\
0.056 \\
0.007 \\
\end{array}$ & $\begin{array}{l}0.01 \\
0.05 \\
0.01 \\
\end{array}$ \\
\hline & DMCF20 & ND & - & - \\
\hline & DMCF21 & ND & - & - \\
\hline & DMCF22 & ND & - & - \\
\hline & DMCF23 & ND & - & - \\
\hline & DMCF24 & $\begin{array}{l}\text { Chlorpyrifos } \\
\text { Quinalphos }\end{array}$ & $\begin{array}{l}0.03 \\
0.296 \\
\end{array}$ & $\begin{array}{l}0.05 \\
0.01 \\
\end{array}$ \\
\hline \multirow[t]{6}{*}{ Karwan Bazar } & DMCF25 & ND & - & - \\
\hline & DMCF26 & ND & - & - \\
\hline & DMCF27 & ND & - & - \\
\hline & DMCF28 & ND & - & - \\
\hline & DMCF29 & Dimethoate & 0.06 & 0.02 \\
\hline & DMCF30 & ND & - & - \\
\hline
\end{tabular}

In this study, among the 30 analyzed samples of cauliflower, 5 samples (16.7\% of the total no. of samples) contained pesticide residues and 25 samples ( $83.3 \%$ of the total number of samples) contained no detectable residues of the sought pesticides. The findings of the present study are in a good agreement with the findings of Akter et al. (2017), they found that among the 50 analyzed samples, 11 (22\% of the total number of the samples) contained residues of diazinon, dimethoate, quinalfos, and chlorpyrifos in eggplant collected from Mymensingh district of Bangladesh, of which, 2 had multiple pesticide residues and 5 contained residues above the EUMRLs. The results of this study also supported by the findings of Hasan et al. (2017), they found that among the 50 analyzed samples, 10 samples $(20 \%)$ contained residues of dimethoate and quinalphos in country bean collected from different markets of Dhaka district of Bangladesh.

In case of Banani bazar, 6 samples of cauliflower were collected, among them only one sample (DMCF5) contained multi-residue of chlorpyrifos $(0.022 \mathrm{mg} / \mathrm{kg})$ and quinalphos $(0.121 \mathrm{mg} / \mathrm{kg})$, where the residue of 
chlorpyrifos was below the EU-MRL $(0.05 \mathrm{mg} / \mathrm{kg})$ and the residue of quinalphos was above the EU-MRL $(0.01$ $\mathrm{mg} / \mathrm{kg}$ ). From Rampura Bazar, among the 6 collected samples of cauliflower, one sample (DMCF11) contained multi-residue of chlorpyrifos and quinalphos, where the residue of chlorpyrifos was $0.038 \mathrm{mg} / \mathrm{kg}$, which was below the EU-MRL $(0.05 \mathrm{mg} / \mathrm{kg}$ ) and the residue of quinalphos was $0.046 \mathrm{mg} / \mathrm{kg}$, which was above the EUMRL $(0.01 \mathrm{mg} / \mathrm{kg})$. In case of Mohammadpur krishi market, none of the analyzed samples contained residues of the sought pesticides among the 6 collected samples of cauliflower.

Among the six analyzed samples of cauliflower collected from Jatrabari bazar, one sample (DMCF19) had multiple pesticide residues of acephate $(0.008 \mathrm{mg} / \mathrm{kg})$, chlorpyrifos $(0.056 \mathrm{mg} / \mathrm{kg})$ and quinalphos $(0.007$ $\mathrm{mg} / \mathrm{kg})$, where the level of residue of acephate and quinalphos were below the EU-MRL $(0.01 \mathrm{mg} / \mathrm{kg})$ and the level of residue of chlorpyrifos was above the EU-MRL $(0.05 \mathrm{mg} / \mathrm{kg}$ ), and another sample (DMCF24) had multiple residue of chlorpyrifos and quinalphos, where the level of chlorpyrifos residue $(0.03 \mathrm{mg} / \mathrm{kg})$ was below the EU-MRL $(0.05 \mathrm{mg} / \mathrm{kg})$ and the level of quinalphos residue $(0.296 \mathrm{mg} / \mathrm{kg})$ was above the EU-MRL $(0.01 \mathrm{mg} / \mathrm{kg}$ ). In case of Karwan bazar, only one sample (DMCF29) contained residue of dimethoate among the 6 analyzed samples. The level of detected dimethoate residue was $0.06 \mathrm{mg} / \mathrm{kg}$, which was above the EU-MRL $(0.02 \mathrm{mg} / \mathrm{kg})$.

\subsection{Pesticide residues in cucumber}

The concentrated extracts of cucumber samples collected from different markets were analyzed by GC-2010 (Shimadzu) with Flame Thermionic Detector (FTD) with the pre-set parameters. The levels of pesticide residues found in the analyzed cauliflower samples and their maximum residue levels are outlined in Table 2.

Table 2. The level of residues $(\mathrm{mg} / \mathrm{kg})$ of different pesticides found in the analyzed cucumber samples.

\begin{tabular}{|c|c|c|c|c|}
\hline Area of collection & Sample ID & Detected pesticides & $\begin{array}{l}\text { Level of residues } \\
(\mathrm{mg} / \mathrm{kg})\end{array}$ & $\begin{array}{l}\text { EU-MRLs } \\
(\mathrm{mg} / \mathrm{kg})\end{array}$ \\
\hline \multirow[t]{4}{*}{ Banani Bazar } & DMCU1 & ND & - & - \\
\hline & DMCU2 & $\mathrm{ND}$ & - & - \\
\hline & DMCU3 & ND & - & - \\
\hline & DMCU4 & ND & - & - \\
\hline \multirow[t]{4}{*}{ Rampura Bazar } & DMCU5 & ND & - & - \\
\hline & DMCU6 & ND & - & - \\
\hline & DMCU7 & ND & - & - \\
\hline & DMCU8 & ND & - & - \\
\hline \multirow{4}{*}{$\begin{array}{l}\text { Mohammadpur Krishi } \\
\text { Market }\end{array}$} & DMCU9 & Quinalphos & 0.008 & 0.01 \\
\hline & DMCU10 & ND & - & - \\
\hline & DMCU11 & $\mathrm{ND}$ & - & - \\
\hline & DMCU12 & ND & - & - \\
\hline \multirow[t]{4}{*}{ Jatrabri Bazar } & DMCU13 & $\mathrm{ND}$ & - & - \\
\hline & DMCU14 & ND & - & - \\
\hline & DMCU15 & ND & - & - \\
\hline & DMCU16 & ND & - & - \\
\hline \multirow[t]{4}{*}{ Karwan Bazar } & DMCU17 & Chlorpyrifos & 0.04 & 0.05 \\
\hline & DMCU18 & ND & - & - \\
\hline & DMCU19 & ND & - & - \\
\hline & DMCU20 & ND & - & - \\
\hline
\end{tabular}

In total 20 cucumber samples were analyzed in this study. Out of 20 analyzed samples, 2 samples (10\% of the total no. of samples) contained pesticide residues and 18 samples (90\% of the total number of samples) contained no detectable residues of the sought pesticides. The present results can be compared to Parven et al. (2021). They have collected 70 samples of country bean and yard long bean samples from Bogura district of Bandgladesh, where they found $11 \%$ country bean and $14 \%$ yard long bean samples were contaminated by pesticide residues. The results of this study also supported by the findings of Islam et al. (2019b), they found that among the 65 analyzed eggplant samples, 8 (12.3\% of the total number of samples) were contaminated with pesticide residues and all of the contaminated samples contained residues above the Maximum Residue Limit (MRL) set by European Commission (EC) collected from different markets of Savar, Dhaka of Bangladesh.

In case of Banani bazar, Rampura bazar and Jatrabari bazar, none of the analyzed samples was found contaminated with the selected pesticides among the 4 analyzed samples collected from each aforementioned 
location. Besides, out of 4 analyzed samples collected from Mohammadpur krishi market, one sample (DMCU9) contained quinalphos residue $(0.008 \mathrm{mg} / \mathrm{kg})$, which was below the EU-MRL $(0.01 \mathrm{mg} / \mathrm{kg})$. In case of Karwan bazar, one sample had chlorpyrifos residue $(0.04 \mathrm{mg} / \mathrm{kg})$ among the 4 analyzed samples. Considering the maximum residue limit $(0.05 \mathrm{mg} / \mathrm{kg})$ set by European Union, the level of detected chlorpyrifos residue was below the EU-MRL.

\section{Conclusions}

In this study, a total of 50 vegetable samples comprised of 30 samples of cauliflower and 20 samples of cucumber collected from different retail markets (Banani Bazar, Rampura Bazar, Mohammadpur Krishi Market, Kawran Bazar and Jatrabari Bazar) of Dhaka district, Bangladesh were analyzed for the quantification of pesticide residues to ensure food safety. Out of 30 analyzed samples of cauliflower, 5 samples $(16.7 \%$ of the total number of samples) contained residues of chlorpyrifos, quinalphos, acephate and dimethoate at a level above the EU-MRL. However, among the 20 analyzed samples of cucumber, only 2 samples (10\% of the total samples) contained residues of quinalphos and chlorpyrifos at a level being below the EU-MRLs. This study will help to understand the residual contamination of studied vegetables in the study area and will help the policy planners to take necessary steps for the reduction of pesticide residue load in vegetables.

\section{Acknowledgements}

The authors are grateful to Md. Kamal Hossain in the Pesticide Analytical Laboratory, Pesticide Research \& Environmental Toxicology Section, Entomology Division, Bangladesh Agricultural Research Institute, Gazipur1701, Bangladesh for his kind cooperation during the present study.

\section{Conflict of interest}

None to declare.

\section{Authors' contribution}

Conceptualization: Mohammad Dalower Hossain Prodhan; Methodology: Mohammad Dalower Hossain Prodhan, Rakibul Hasan, Md. Mahadi Alam and S M Mizanur Rahman; Formal analysis and investigation: Rakibul Hasan, Mohammad Dalower Hossain Prodhan and Md. Mahadi Alam; Writing - original draft preparation: Mohammad Dalower Hossain Prodhan, Rakibul Hasan and Deeder Sultana; Writing - review and editing: Mohammad Dalower Hossain Prodhan, S M Mizanur Rahman and Deeder Sultana; Supervision: Mohammad Dalower Hossain Prodhan and S M Mizanur Rahman.

\section{References}

Ahmed MS, MDH Prodhan, A Begum, M Afroze and D Sarker, 2021. Estimation of residue degradation of cypermethrin and chlorpyrifos in brinjal, tomato and cauliflower under supervised field trial. Asian Australas. J. Biosci. Biotechnol., 6: 60-67.

Ahmed MS, MDH Prodhan, A Begum, M Afroze and D Sarker, 2021a. Organophosphorus pesticide residues detected in eggplant and tomato samples collected from different regions of Bangladesh. Asian Australas. J. Food Saf. Secur., 5: 27-31.

Ahmed MS, A Begum, MDH Prodhan and D Sarker, 2019. Analysis of pesticide residue in vegetables collected from nine different regions of Bangladesh using Gas Chromatography. Asian Australas. J. Food Saf. Secur., 3: 23-26.

Aktar MA, R Khatun and MDH Prodhan, 2017. Determination of pesticide residues in eggplant using modified QuEChERS Extraction and Gas chromatography. Int. J. Agron. Agri. Res., 11: 22-31.

Anonymous, 2000. Annual report 1999-2000, Entomology Division, Bangladesh Agricultural Research Institute, Joydebpur, Gazipur, Bangladesh.

Antle JM and PL Pingali, 1994. Pesticides, Productivity and Farmer Health: A Philippine Case Study, American Journal of Agril. Economics, 76: 418-430.

Dias JS and E Ryder, 2011. World Vegetable Industry: Production, Breeding, Trends, Hort Review, 38: 299356.

European commission, 2005. EU pesticide residue MRLs. regulation no. 396/2005. http://ec.europa.eu/sanco_pesticides/public/index.cfm.

Habib M, A Kaium, MSI Khan, MDH Prodhan, N Begum, MTI Chowdhury and MA Islam, 2021. Residue level and health risk assessment of organophosphorus pesticides in eggplant and cauliflower collected from Dhaka city, Bangladesh. Food Res., 5: 369-377. 
Hasan R, MDH Prodhan, SMM Rahman, R Khanom and A Ullah, 2017. Determination of organophosphorus insecticide residues in country bean collected from different markets of Dhaka. J. Env. Anal. Toxicol., 7: 489.

Hossain MS, MM Rahman, KH Kabir, MRU Miah and MDH Prodhan, 2014. Determination of Pre Harvest Interval (PHI) for cypermethrin and acephate in yard-long bean under supervised field trial. Bangladesh J. Entomol., 24: 101-115.

Islam MS, MR Rahman, MDH Prodhan, D Sarker, MM Rahman and MK Uddin, 2021. Human health risk assessment of pesticide residues in pointed gourd collected from retail markets of Dhaka city, Bangladesh. Accredit. Qual Assur., 26: 201-210.

Islam MA, A Ullah, M Habib, MTI Chowdhury, MSI Khan, A Kaium and MDH Prodhan, 2019. Determination of major organophosphate pesticide residues in cabbage collected from different markets of Dhaka. Asia Pac. Environ. Occup. Health J., 5: 30-35.

Islam MS, MDH Prodhan and MK Uddin, 2019a. Analysis of the pesticide residues in bitter gourd using modified QuEChERS extraction coupled with Gas Chromatography. Asia Pac. Environ. Occup. Health J., 5: 6-15.

Islam MS, MDH Prodhan and MK Uddin, 2019b. Determination of major organophosphorus pesticide residues in eggplant using QuEChERS extraction and gas chromatography. Int. J. Innov. Sci. Res. Technol. 4: 212219.

Islam MW, KMG Dastogeer, I Hamim, MDH Prodhan and M Ashrafuzzaman, 2014. Detection and quantification of pesticide residues in selected vegetables of Bangladesh. J. Phytopathol. Pest Manag., 1: 1730.

Kabir KH, MA Rahman, MS Ahmed, MDH Prodhan and MW Akon, 2008. Determination of residue of diazinon and carbosulfan in brinjal and quinalphos in yard long bean under supervised field trial. Bangladesh J. Agril. Res., 33: 503-513.

Kabir KH, MA Rahman, MS Ahmed, MDH Prodhan and MW Akon, 2008a. Quantitative analysis of some commonly used insecticides in vegetables. Bangladesh J. Agriculturist, 1: 259-264.

Kabir KH, M Abdullah, MDH Prodhan, MS Ahmed and MN Alam, 2007. Determination of carbofuran residue in the samples of sugarcane and soil of sugarcane field. The Agriculturist, 5: 61-66.

Kumari B, VK Madan, J Singh, S Singh and TS Kathpal, 2004. Monitoring of pesticidal contamination of farmgate vegetables. Earth Environ. Sci., 90: 65-71.

McIntyre AN, N Allision and DR Penman, 1989. Pesticides: Issues and Options for New Zealand. Ministry for the Environment, Wellington, New Zealand, 7: 29.

Nahar KM, MSI Khan, M Habib, SM Hossain, MDH Prodhan and MA Islam, 2020. Health risk assessment of pesticide residues in vegetables collected from northern part of Bangladesh. Food Res., 4: 2281-2288.

Parven A, MSI Khan, MDH Prodhan, K Venkateswarlu, M Mallavarapu and IM Meftaul, 2021. Human health risk assessment through quantitative screening of insecticide residues in two green beans to ensure food safety. J. Food Compos. Anal., 103: 104121.

Prodhan MDH, M Afroze, A Begum and D Sarker, 2021. Determination of organophosphorus and synthetic pyrethroid pesticide residues and their variability in large size fruit crops. J. Sci. Food. Agric. 101: 48474854.

Prodhan MDH, M Afroze, A Begum, MS Ahmed and D Sarker, 2021a. Optimization of a QuEChERS based analytical method for the determination of organophosphorus and synthetic pyrethroid pesticide residues in betel Leaf. Intern. J. Environ. Anal. Chem. https://doi.org/10.1080/03067319.2021.1873311

Prodhan MDH, MS Ahmed, NK Dutta, D Sarker and SN Alam, 2021b. Determination of organochlorine and synthetic pyrethroid pesticide residues in water samples collected from different locations of Bangladesh. J. Biophys. Chem., 12: 11-21.

Prodhan MDH, EN Papadakis and E Papadopoulou-Mourkidou, 2018. Variability of pesticide residues in eggplant units collected from a field trial and marketplaces in Greece. J. Sci. Food. Agric., 98: 2277-2284.

Prodhan MDH and SN Alam, 2018a. Determination of multiple organochlorine pesticide residues in shrimp using modified QuEChERS extraction and gas chromatography. SAARC J. Agri., 16: 81-93.

Prodhan MDH, MW Akon and SN Alam, 2018b. Determination of pre-harvest interval for quinalphos, malathion, diazinon and cypermethrin in major vegetables. J. Environ. Anal. Toxicol., 8: 553.

Prodhan MDH, MW Akon and SN Alam, 2018c. Decontamination of organophosphorus insecticide residues from eggplant and yard long bean. Int. J. Expt. Agric., 8: 6-9. 
Prodhan MDH, EN Papadakis and E Papadopoulou-Mourkidou, 2016. Variability of pesticide residues in cauliflower units collected from a field trial, and market places in Greece. J. Environ. Sci. Health, Part B., 51: 644-653.

Prodhan MDH, EN Papadakis and E Papadopoulou-Mourkidou, 2016a. Analysis of pesticide residues and their variability in cabbage using QuEChERS Extraction in combination with LC-MS/MS. Food Anal. Methods, 9: 3470-3478.

Prodhan MDH, EN Papadakis and E Papadopoulou-Mourkidou, 2015. Determination of multiple pesticide residues in eggplant with liquid chromatography-mass spectrometry. Food Anal. Methods, 8: 229-235.

Prodhan MDH, EN Papadakis and E Papadopoulou-Mourkidou, 2015a. Analysis of pesticide residues in melon using QuEChERS extraction and liquid chromatography triple quadruple mass spectrometry. Int. J. Env. Anal. Chem., 95: 1219-1229.

Prodhan MDH, MA Rahman, MS Ahmed and KH Kabir, 2010. Pesticide residues in fish samples collected from different fish cultivation regions of Bangladesh. SAARC J. Agri., 8: 53-64.

Prodhan MDH, MA Rahman, MS Ahmed and KH Kabir, 2009. Quantification of organophosphorus and organochlorine insecticide residues from fish samples using smiple GC technique. Bangladesh J. Agriculturist, 2: 197-204.

Rahman AM, 1999. Effect and residues of two selected insecticides applied for control of brinjal shoot and fruit borer in eggplant. An MS Thesis submitted to BSMRAU, Gazipur, Bangladesh, pp.1-4.

Wargovich MJ, 2000. Anticancer properties of fruits and vegetables. Hort. Sci., 35: 573-575.

Yang RY, SCS Tsou, TC Lee, WJ Wu, PM Hanson, G Kuo, LM Engle and PY Lai, 2006. Distribution of 127 edible plant species for antioxidant activities by two assays. J. Sci. Food Agric., 86: 2395-2403. 